\title{
A Sustainable Approach: Increasing Students' Information-Technology Competences and Job-Seeking Capabilities through Course Redesign Using FIT Framework and Active Learning Pedagogy
}

\author{
Tung-Ming Pan 1,2,*(D) and Kuo-Chin Fan ${ }^{1}$ \\ 1 Department of Computer Science \& Information Engineering, National Central University, \\ Chung-Li 320, Taiwan; kcfan@csie.ncu.edu.tw \\ 2 Holistic Education Center, Fu Jen Catholic University, New Taipei City 242, Taiwan \\ * Correspondence: macgyver@mail.fju.edu.tw
}

Received: 31 March 2020; Accepted: 14 May 2020; Published: 17 May 2020

check for updates

\begin{abstract}
FIT, Fluency with Information Technology, was developed by the National Research Council, USA in 1999. A FIT individual is defined as someone who can build new knowledge based on his/her prior knowledge, be self-sustaining when changes happen, and find solutions creatively to solve more complicated problems. Using FIT framework and active learning concept to restructure an information technology (IT) course is a sustainable approach to helping students learn, think, and adapt to the constant changes of technology. This article illustrates how FIT framework helped redesign a general education Network Resources and Applications course to enhance students' IT competences and job-seeking capabilities. It describes (1) the importance of IT education in Taiwan to sustain its high-tech economy, (2) the trend of IT literacy education and active learning presented in literature, (3) how FIT intellectual framework was applied to redesign this course and how active learning strategies were incorporated into teaching, and (4) how pre-test, post-test, and Likert-Scale statistical methodology were used to measure the effectiveness of this new approach. Test results indicated that the new approach did effectively facilitate teaching and increase students' learning performance, which is consistent with the findings presented in the literature.
\end{abstract}

Keywords: Fluency with Information Technology (FIT); active learning strategies; information technology literacy; network resources and applications; technology-enabled active learning tools; sustainable education

\section{Introduction}

\subsection{Background}

Underpinned by ever-changing information technology, the Internet has penetrated almost every aspect of our lives. Its impact on the entire globe, from economy, to social culture, to politics, to education, has been abundantly noted in the literature since its debut in the 1970s. However, by the mid-1990s, the ways in which information technology was changing the world grew rapidly. Many countries around the globe began establishing their own National Information Infrastructure (NII) and revamping their education systems by following the United States' footprint [1] with localized modifications. Taiwan was no exception.

Taiwan's NII project in 1994 aimed to equip the country as an "Internet hub in Asia Pacific area" [2] to continue the success of its ICT (Information and Communication Technology) high-tech industrial economy, and further to transform the country into a globalized "knowledge-based society" [3]. Within 
three years of its launch, Taiwan's Internet backbone interconnected not only all other Asia Pacific countries but also all continents. Additionally, its education systems at all levels were interconnected and started to receive Internet service [4].

In conjunction with the nationwide implementation of NII project, Taiwan's Ministry of Education (TMOE) took this opportunity to launch a series of well-thought-out educational reforms. Some highlights included: distributing computer hardware, software and CAI (Computer-Assisted Instruction) programs to all classrooms in the elementary and secondary schools for teaching and learning technology; adding computer literacy as a required curriculum; promoting and enhancing science, technology, and engineering education; integrating information technology education into curriculum in all subject areas; establishing Internet e-Learning (i.e., distance learning) system to expand technology training programs as well as to provide all citizens with continuing education and lifelong learning opportunities through National Open University Program [5,6]. In addition, to help the country to remain globally competitive in technology-based economy world, TMOE initiated several fundamental works including working with business sectors to establish cooperative R\&D (Research and Development) programs, fostering students' talent and increasing students' job opportunities, establishing technology training and continuing education programs to increase citizens' information technology competence [3]. It is worth noting that Taiwan is currently ranked at 12th place out of 141 countries in terms of ICT industrial economy, up three notches from 2018's ranking, according to World Economic Forum [7]. Hence, the importance of advancing information technology education in Taiwan cannot be understated. It holds the key to staying competitive and prosperous within the global technology economy community.

\subsection{Fu Jen Catholic University's Information Technology Literacy Program}

$\mathrm{Fu}$ Jen Catholic University, with which the authors are affiliated, is a liberal art university in Taiwan. It currently has more than 26,000 enrolled students, including undergraduates and graduates [8]. In early 2000, the Holistic Education Center [9] was established to charge the integration and organization of the required curriculum. The required curriculum consists of three types of courses: Fundamental core courses, core skills, and general education courses. All undergraduate students are required to earn a total of 32 credits by taking the courses specified in these three groups before graduation. Network Resources and Applications, a two-credit course, is included in the group of general education that focuses on literacy in Science and Information Technology areas. This course can also be used by students outside computer science field to fulfill their information literacy core skills requirement.

\subsection{Motivations and the Purposes of This Article}

Since computer literacy has been integrated into the curriculum at all elementary and secondary schools in Taiwan, hopefully students should already have basic computer skills to perform productivity works and find information on the Internet by the time when they are admitted to college. Including information technology literacy education at the college level ensures that students can keep pace with fast changing technology advances. This also allows them to learn new skills that support their disciplinary needs. In addition, these courses provide opportunities for students to build a foundation for their technology-based career goals and consequently stay relevant to the demands of the technology job market. This allows the country to sustain its ICT industrial economy on the world stage.

Taiwan Executive Yuan conducted a survey in 2010 with the goal of improving college graduates' employment prospects [10]. In addition to other results, the report concluded with two suggestions pertaining to teaching faculty. The first suggestion was that faculty redesign their courses by integrating core literacy elements into the courses they were teaching. By doing that, students would be able to learn and to improve their core literacy abilities semester by semester until they graduate. The second suggestion was that changing teaching strategy could benefit students' learning outcomes as well 
(pp. 364-365). A copy of the report was distributed to each faculty and faculty were encouraged to take action.

In that spirit, the authors of this article then decided to redesign the Network Resources and Applications course and adopt active learning strategies. After more than a year's preparation, this idea was then put to the test in Fall 2012 and Spring 2013. To evaluate the effectiveness of these changes, two tests (i.e., pre-test and post-test) were conducted at the beginning and at the end of each semester, respectively. Thus, the purpose of this article is fivefold: (1) to describe the efforts made by Taiwan's government to sustain its high-tech economy, and what had motivated the authors to make teaching practice changes, (2) to review the literature on the evolution of information technology literacy and fluency, and active learning, (3) to illustrate how FIT (Fluency with Information Technology) Framework (The National Research Council, USA, 1999) was applied to redesign this course, and how active learning strategies were incorporated, (4) to evaluate the effectiveness of the new approach using pre-test, post-test, and Likert Scale statistical methodology, and (5) lastly to share the findings with professionals in the same field as well as to solicit comments for future research and improvement.

\section{Literature Review}

\subsection{Information Technology Literacy and Fluency}

Although Taiwan's ICT industry is prosperous on the world stage, the country is still using IT literacy (ITL) as a formal term instead of ICT literacy (ICTL). After extensive literature search, the authors of this article found that ICT literacy focuses much more on information search, retrieval, evaluation, and use, as well as creation of information using a networked environment. In contrast, we found that ITL focuses much more on technology itself, and much less on the manipulation of information. Therefore, the authors of this article decided to concentrate on ITL's evolution.

Information Technology (IT) has transformed the traditional way that information and knowledge are produced, packaged, and disseminated. Today, information and technology are closely integrated. Therefore, having IT basic skills is a prerequisite for accessing information to acquire new knowledge and new skills. In addition, IT-based applications, tools, platforms, and devices are widely used by people from every walk of life to simplify and accomplish more sophisticated tasks. IT-based tools help students observe and visualize natural phenomena in real-time [11], help scientists conduct complex research [12], and help medical staff deliver healthcare from far away [13]. These are just a few examples demonstrating the indispensable role played by IT in our day-to-day endeavors. The importance of IT literacy education is undoubtedly self-evident.

What is IT literacy? Is IT literacy same as computer literacy? Although a plethora of studies on teaching computer literacy have been published since early 1980s, the literature on IT literacy is quite scarce. Due to the changing nature of technology advances and different perceptions held by various researchers [14-18], both terms had never been defined consistently. Nevertheless, among those studies, Osborne [19], Halaris [20], and the National Research Council, USA [21] presented their point of view in the most concrete and systematic manner to illustrate what IT literacy was about, especially for those who were outside the computer science field.

Osborne's study [19] was the earliest one found by the authors of this article on IT literacy. It pointed out that most "key" aspects between computer literacy and IT literacy were similar but IT literacy should go beyond mastering "computer operational skills" to include all "electronic means" that permitted "the acquisition, storage, manipulation, transmission, display and use of information" (pp. 343-344). Osborne also argued that an IT literate should be a critical thinker and have self-efficacy, knowing "personal uses for IT in a range of situations (study, work or domestic)," perceiving "possible future and new uses of IT," and having the ability to "analyze and evaluate attitudes and values associated with the technology and applications" (p. 344). Osborne further suggested that it might be necessary to have different set of IT competencies for each individual discipline due to the fast growth of IT advances associated with each discipline. 
Halaris [20] used "computing literacy" instead of IT literacy and considered it as a progressive learning process like a four-stage continuum with one end starting with the awareness of computing and proceeding with "computing literacy," "computing fluency," and "computing expertise" (p. 321). Along this continuum, computer users at each stage were categorized as an "indifferent" tool user, a "tool abider", a "tool adapter", and then a "tool builder". With that, he then defined a computing literate as those who reached the last stage and had "mastered a well-rounded set of computing-related knowledge and skills" (p. 320). In the meantime, a computing literate could further develop "competencies to use computing." He also pointed out that because not everyone wanted to comprehend everything of IT, this "broad-based" approach provided room for an individual to decide his/her own level of competence to achieve. He considered the second stage of the continuum as computer literacy and a foundational components of IT literacy.

The National Research Council (NRC), USA [21] published a report entitled Being Fluent with Information Technology. Its main purpose was to find a universally acceptable "interpretation" of IT literacy education. NRC first addressed the scope of information technology available at that time, which included a broad range of computing equipment, from general purpose to embedded devices to "the science underlying the technology" (NRC, USA, 1999, p. viii). NRC next agreed that constant learning was inescapable because of the ever-changing nature of IT advances. NRC also recognized that not everyone wanted to master every aspect of the technology. Thus, particularly for IT users who were outside computer science field, NRC suggested that having a profound understanding of the underlying concepts of IT be the most effective way to adapt to the rapid changes of technology. "Fluency" was then chosen to depict "the ability to re-formulate knowledge, to express oneself creatively and appropriately, and to produce and generate information (rather than simply to comprehend it)" (p. viii). The term "fluency with information technology" (FIT) was then used to represent a higher level of IT capabilities than IT literacy. NRC also perceived the learning process as a continuum but with no ending stage. An individual could decide the position on the continuum he/she wanted to be. Students were encouraged to make up their minds early on.

In support of its new "interpretation", NRC further constructed an "intellectual framework" of FIT consisting of three "co-equal" components: (1) "contemporary skills", (2) "foundational concepts", and (3) "intellectual capabilities" (pp. 2-3). The three components represent "three different kinds of knowledge," and each enhances the others (p. 3). With contemporary skills, a FIT individual could perform computing tasks effectively; with conceptual understanding, a FIT individual could make adjust smoothly and pick up new skills quickly when technology changes; with intellectual capacities, a FIT individual could expand his/her knowledge to stay on top of changes and figure out how to use more sophisticated tools to resolve more complex situations. Moreover, in order to be able to adapt to changes, constant learning would be necessary. That would help cultivate a lifelong learner, which was the ultimate goal of FIT. To integrate this framework into curriculum, NRC highly recommended starting the implementation from four-year colleges and universities and using "project-based approach" to teach.

\subsection{Active Learning as a Teaching Strategy}

\subsubsection{Background}

The idea of active learning for higher education started gaining traction in the 1980s according to Bonwell and Eison [22]. Both authors provided a thorough overview of the meanings of active learning, teaching techniques that could encourage active learning, obstacles to implementation, and suggestions for promoting active learning. Faculty were encouraged to move away from traditional, lecturing-only style of teaching by adopting active learning strategies to engage students in knowledge exploration and high-order thinking in classroom settings. Since then, research in this area has been flourishing [23-27]. 
Bonwell and Eison [22] defined active learning as strategies that incorporated "instructional activities involving students in doing things and thinking about what they are doing" (p. iii). They presented a list of methods that had been commonly used in traditional classrooms previously. Some were simple and easy-to-adopt: pausing regularly during lecturing to ask or discuss questions; showing pictures or graphics to illustrate complex concepts and ideas; giving time to students to write and summarize what had been taught. Some were techniques employing old audiovisual and early computer-based technology to motivate and help students retain the knowledge that they were learning. Games, simulation, debates, role playing, peer-teaching, etc., were other techniques that could generate interactions with or without using technology.

Prince [27] noted that the "core elements of active learning were student activity and engagement in the learning process" (p. 223) for the engineering disciplines. He focused on the more sophisticated strategic models such as collaborative learning, cooperative learning, and problem-based learning (PBL). They were team-based but each had distinct emphases. He argued that if faculty could have these emphases in mind in formulating "meaningful learning activities" for classroom instruction, students would reach learning outcomes effectively and in turn improve their academic achievement, interpersonal interactions, self-esteem, attitudes, etc.

Project-based, inquiry-based, case-based, and discovery-based learning are other sophisticated approaches that require pre-classroom instructional planning in order to create an effective active learning environment. Each approach has its own set of core elements as well [23].

Nevertheless, the theory behind all these active learning models is rooted in constructivism theory according to Cattaneo [23]. Constructivism promotes that "education should be about learning not teaching; learning as in a place where individuals construct their own knowledge personally and socially..." (pp. 145-146). In contrast, lecturing is emphasized less. Instead, teachers spend more time in planning and designing their courses to provide well-structured scaffolding at each level of learning. During the learning process, students "are encouraged to build on prior knowledge, think critically, reflect, and present their information independently and in small groups." They build new knowledge progressively and gain the ability to learn independently. As their capabilities increases, they become responsible for both the content and process of learning" (p. 146). In this manner, students concentrate on learning and teachers take a "non-expert, facilitator, or guiding role" to ask questions, answer questions, and provide guidance when needed. Cattaneo then points out that "learner-centeredness has become one of the most distinctive epistemological features shared by all active learning strategies, methods, or approaches." However, limitations exist. The degree of success depends on a teacher's capacity and students' maturity

\subsubsection{Technology-Enabled Active Learning Tools}

Preparing students to deal with the constant change of information technology had become an important issue for countries around the world since the 1980s [28]. Using pedagogic strategies to incorporate technology "into curriculum and classroom activities" seemed to be a most desired solution, as the integration could help students learn not only about the technology they were using, but also the course content at the same time [28]. Since then, technology-enabled learning tools had started to grow rapidly and the benefits of using those tools to engage students in leaning have been noted prolifically in the literature.

To date, a variety of large-scale and integrated web-based learning management systems (LMS) have become an indispensable component of the campus education infrastructure. Although these systems have different names (e.g., Blackboard, Moodle, iCan, etc.), they all offer many similar functionalities such as email, discussion forum, quiz, and grade book at the basic level to support interactivity and collaboration between instructors and students as well as between peers. Tools for course content delivery offer instructors numerous ways to display or transmit content pedagogically through videos, audios, PowerPoint slides, and other formats at their own discretion. Students can access course content anytime and anywhere they wish. They can learn at their own pace. Furthermore, 
the system can now not only support in-class activities, but also outside classroom activities as well. Flipping classroom, hybrid classroom, blended learning are the emerging modes of learning derived from these web-based and technology-enhanced learning systems, which help shift the classroom dynamics from teacher-centered to learner-centered learning.

Reid and Weber [29] used technology-enabled active learning tools to teach a "Business Ethics Topics in Business Law" course. They noted that "utilizing technology-enabled active learning tools was an effective pedagogical approach..." (p. 283). Snowball and Mostert [30] had used LMS to teach a large first year introductory macroeconomic course in a blended learning setting. They particularly used the built-in discussion forum to increase the interactivity, allowing students to share ideas and work on problems as a group. They noted that instructors could "respond to problem areas quickly and be more sensitive to students' learning needs." Schroeder-Moreno [31] found that teaching "strategies that enhance frequent interactions and student engagement in online courses can help keep students connected to the material and to each other, and motivated, even in virtual space" (p. 21).

Mitchell, Petter, and Harris [24] surveyed active learning strategies specifically used for Information Systems (IS) discipline. Because of the tremendous opportunities offered by emerging modes of learning environments (e.g., flipped classroom, blended learning, etc.), they redefined active learning as "one time or ongoing student exercises that are introduced in the classroom to encourage student thinking and participation in an effort to engage students in the learning process" (p. 23). They gathered 20 successful active learning strategies. Among them, many were student-led methods that could get them involved in using technology and high-order thinking, and allow students to digest, assimilate, and build new knowledge on their own. They concluded that students needed to learn by doing and by working with each other on projects; students needed to present the results in front of the class and receive feedback from their teachers and peers. They believed that faculty could reap the best learning outcomes by "redesigning their courses to include active learning components" (p. 23).

Although a small number of studies did not find any benefit of active learning, "plentiful empirical support for the approach" existed in the literature [26]. By examining both traditional and technology-enabled active learning strategies, Patton picked five methods considered most effective and beneficial. They were pausing technique, clickers, flipping-classroom approach, peer reviews, and games. Benefits included increased classroom interactivity, improved learning of high-level thinking and collaborative skills, and improved ability to apply prior knowledge while enforcing learner-centered learning at the same time. Patton then concluded that learning outcomes could be improved "with a more active learning approach, where the educator takes on the role of a facilitator, taking into consideration students' learning styles, attention span and specific needs" (p. 139).

\section{Course Redesign and Incorporating Active Learning Strategies}

\subsection{Restructuring Course Content by Applying FIT Intellectual Framework}

Given the above, the rationales and explanations of FIT developed by NRC, USA (1999) were the clearest and most convincing. Thus, we decided to use its intellectual framework (i.e., concepts, skills, and capabilities) as bases to set aims, reconstruct course content, design projects, define learning outcomes, and develop pedagogic strategies for this course. Additionally, as technology advanced rather rapidly, the scope of this course had to be expanded accordingly. Teasing outdated materials and augmenting underpinning components were necessary.

The aims for this two-credit course were (1) to help students gain basic foundational knowledge of network technology, (2) to help students develop skills to access and use emerging network resources and applications for their academic and personal needs, (3) to inspire students to further strengthen their high-order thinking and reasoning capabilities during knowledge building process, with the goal of becoming a critical thinker, and (4) to cultivate an awareness of the risks incurred by the fast-changing information technology environment. 
Table 1 shows the reconstructed topics. Subtopics with an appended asterisk were new content. Additionally, subtopics in italics were concepts to be taught. They were the concepts component based on FIT intellectual framework.

Table 1. Restructured Topics of Network Resources and Applications.

\begin{tabular}{ll}
\hline Unit \# & Topics \\
\hline 1. & General Introduction: \\
& A brief history of network evolution, the Internet, World Wide Web (WWW), Impacts on \\
& personal life, society, and the globe. \\
& Network basics: \\
a. Terminology; \\
b. Network topology-OSI (Open Systems Interconnection Reference Model) model, required \\
hardware and software components, data transmission methods, client/server configuration, LAN \\
(Local Area Network) and WAN (Wide Area Network); \\
c. Broadcasting, multicasting, and point-to-point (P2P) connection; \\
d. Internet backbone, TCP/IP (Transmission Control Protocol/Internet Protocol), DNS (Domain \\
Name Service), web address composition and domain symbols, Intranet, Extranet, http:// vs https://, \\
ISP (Internet Service Provider); \\
e. Microsoft Windows network functions, Remote Desktop Protocol (RDP), and firewall rules *; \\
f. Other Remote Desktop connection applications: Google Chrome Remote Desktop (CRD), \\
VNC ${ }^{\circledR}$ Viewer, and TeamViewer *; \\
g. Wireless network, connection methods (WAP (Wireless Application Protocol), GPRS (General \\
Packet Radio Service)), and hot spots; \\
h. Broadband network and required hardware and software components *. \\
2.
\end{tabular}

Network Resources and applications:

a. Email messaging principles, POP3 (Post Office Protocol-Version 3), filter, spam mails, phishing

*, malware, viruses, and other security risks *;

b. Web browser operating principles, useful web browser features (e.g., bookmarks and favorite folders), privacy and security controls *, popular search engines, FTP (File Transfer 3. Protocol) and P2P file transfer;

c. Web 2.0 characteristics and its impacts, social media and Facebook; Open Source software*, freeware *, shareware, etc.;

d. Proxy server and VPN (Virtual Private Network) principles and purposes *;

e. Navigating the University, library networked resources, and Taiwan research resources network.

Emerging Network Resources and Applications, Awareness of Cyber Risks and Safety:

a. Cloud computing basics: virtualization and virtual machine technology; *

b. Google Docs productivity and sharing tools for collaboration and social;

c. Other document sharing and collaboration websites: Evernote, Dropbox, Panoramio, etc.; *

4. d. Intellectual Property Rights (IPR), Creative Commons (CC) Licenses *, regulations and prevention;

e. Cyber-attacks: hackers, crackers, malware, Trojan Hose virus, DDoS (Distributed

Denial-of-Service), ransomware, etc.; *

f. Brief introduction to future networks: 4G, 5G high-speed networks and their physical components. *

* denotes new content. Note: Subtopics in italics font denote concept components.

Table 2 lists the accompanying activities and projects designed for each topic to engage students in active learning. The three knowledge components of FIT framework were identified in each project. The potential learning outcomes in relation to skill and capability categories are listed in the rightmost column of Table 2. 
Table 2. Accompanying Active Learning Activities and Projects.

\begin{tabular}{|c|c|c|}
\hline Unit \# & Topics & $\begin{array}{l}\text { FIT Knowledge Components } \\
\text { and Expectations }\end{array}$ \\
\hline 1 & $\begin{array}{l}\text { General Introductions: } \\
\text { Have students find and share information about both } \\
\text { positive and negative impacts of the Internet they } \\
\text { have heard and experienced so far, either in class or } \\
\text { through the discussion forum facility on the iCan5 } \\
\text { Learning System. }\end{array}$ & $\begin{array}{l}\text { Skills and capabilities: } \\
\text { To find relevant information and } \\
\text { use productivity tools to organize, } \\
\text { present, and share the findings in } \\
\text { class and via the discussion forum. }\end{array}$ \\
\hline 2 & $\begin{array}{l}\text { Network Basics: } \\
\text { a. Learning by exploration: } \\
\text { Assignment 1: Have students } \\
\text { (1) find the configuration of their Internet connection } \\
\text { at home, dorm, or apartment, } \\
\text { (2) identify the connection method used and the } \\
\text { required devices, } \\
\text { (3) issue router commands on a PC to find connection } \\
\text { data (i.e., IP, DNS, etc.), } \\
\text { (4) evaluate the advantages and disadvantages of } \\
\text { each method, } \\
\text { (5) write a summary report with a configuration } \\
\text { drawing attached and share the reports in class and } \\
\text { discussion forum, and } \\
\text { (6) submit the report for grading through iCan5; } \\
\text { b. Learning via slide and video presentations using } \\
\text { flipping-classroom approach: } \\
\text { Assignment 2: Students should watch six selected } \\
\text { YouTube videos on Internet evolution and write a } \\
\text { 300-word report on the most interesting presentation } \\
\text { and submit the report on iCan5; } \\
\text { c. Learning by doing: } \\
\text { Assignment 3: Assigning groups to } \\
\text { (1) try out Microsoft Windows network functions, } \\
\text { including establishing domain and working groups, } \\
\text { setting access and sharing permissions, and } \\
\text { launching remote desktop functions, } \\
\text { (2) establish remote desktop using one of: Google } \\
\text { CRD, VNC }{ }^{\circledR} \text { Viewer, and TeamViewer, } \\
\text { (3) write a report detailing the process and how } \\
\text { sharing is accomplished with screenshots showing } \\
\text { the essential steps achieved successfully, and } \\
\text { (4) submit the report on iCan5; } \\
\text { d. Two in-class online multiple-choice quizzes on } \\
\text { conceptual topics and terminology; }\end{array}$ & $\begin{array}{l}\text { Skills: Students are able to } \\
\text { (1) establish a basic } \\
\text { windows-based network properly } \\
\text { using Microsoft Windows network } \\
\text { function tools, } \\
\text { (2) identify or diagnose what is } \\
\text { needed to solve network } \\
\text { connection problems, and } \\
\text { (3) apply firewall and other } \\
\text { security rules properly to ensure a } \\
\text { safe network connection. } \\
\text { Capabilities: } \\
\text { (1) to observe, think, and identify } \\
\text { the required hardware and } \\
\text { software components needed for } \\
\text { establishing a functional network } \\
\text { and a remote desktop connection, } \\
\text { (2) to understand in general the } \\
\text { structural composition of the } \\
\text { entire Internet and the role of each } \\
\text { essential component, such as IP, } \\
\text { DNS, data packet transmission } \\
\text { methods, etc., } \\
\text { (3) to understand the usefulness } \\
\text { and the negative impacts of the } \\
\text { Internet } \\
\text { (4) to find out how to troubleshoot } \\
\text { and recover a personal network } \\
\text { connection when encountering } \\
\text { problems through critical thinking. }\end{array}$ \\
\hline
\end{tabular}


Table 2. Cont.

\begin{tabular}{|c|c|c|}
\hline Unit \# & Topics & $\begin{array}{l}\text { FIT Knowledge Components } \\
\text { and Expectations }\end{array}$ \\
\hline 3 & $\begin{array}{l}\text { Network Resources and applications: } \\
\text { a. Learning by doing: } \\
\text { Practicing group mailing, filtering, moving incoming } \\
\text { emails to designated folders automatically, managing } \\
\text { discussion threads, password change and update, } \\
\text { creating a group and starting communication within } \\
\text { the group, etc.; } \\
\text { b. Learning via visual presentations using } \\
\text { flipping-classroom approach: } \\
\text { Having students watch slides on network safety, } \\
\text { security risks, and cyber-attacks by presenting case } \\
\text { studies, explaining why, how, and what they are. } \\
\text { This includes hackers, cracker, malware, computer } \\
\text { viruses, DDoS (Distributed Denial of Service), } \\
\text { phishing, Trojan Horse virus, Spoofing, Smurf } \\
\text { attacks, ransomware, etc.), demonstrating prevention } \\
\text { methods and applying secure password rules, and } \\
\text { ISMS (Information Security Management System) } \\
\text { principles and policies, etc. } \\
\text { c. Learning by doing: } \\
\text { Having students create simple web pages using } \\
\text { http:// and https:// access to demonstrate possible } \\
\text { network risks and how browser personal data safety } \\
\text { controls work; } \\
\text { d. Quiz on TCP/IP, DHCP, DNS, etc.; } \\
\text { e. Midterm exam on Email topics; }\end{array}$ & $\begin{array}{l}\text { Skills: Students are able to } \\
\text { (1) manage personal email and } \\
\text { other online accounts including } \\
\text { Facebook effectively, } \\
\text { (2) navigate the University, library } \\
\text { resources, government, and } \\
\text { scientific organization websites to } \\
\text { find information for academic, } \\
\text { research, and personal needs, and } \\
\text { (3) use web browser settings to } \\
\text { change sound, display, and other } \\
\text { features to personal liking, and } \\
\text { (4) use security settings to protect } \\
\text { personal computer and personal } \\
\text { privacy from any possible cyber } \\
\text { risks. } \\
\text { Capabilities: Students can } \\
\text { (1) grasp the basic structural and } \\
\text { functional components of a } \\
\text { website quickly, } \\
\text { (2) protect personal computer } \\
\text { from malicious cyber-attacks, } \\
\text { (3) take appropriate measures to } \\
\text { minimize cyber security risks, } \\
\text { (4) stay safe and secure when } \\
\text { accessing and using networked } \\
\text { resources and applications. }\end{array}$ \\
\hline 4 & $\begin{array}{l}\text { Emerging Network Resources and Applications, } \\
\text { Awareness of Network Risks and Safety: } \\
\text { a. Learning via visual presentation using } \\
\text { flipping-classroom approach: } \\
\text { Have students } \\
\text { (1) watch selected YouTube videos on Cloud } \\
\text { Computing technology basics, applications, and } \\
\text { implications; } \\
\text { (2) have students write a summary report, and } \\
\text { (3) submit the report on iCan5 for grading; } \\
\text { b. Learning by reading and writing: Have students } \\
\text { read selected articles on IPR and CC regulations. } \\
\text { Have students write a report summarizing IPR and } \\
\text { CC, as well as associated regulations, violations, and } \\
\text { violation prevention strategies } \\
\text { c. Learning by observation and exploration: } \\
\text { Taking students to visit Taipei World Commerce } \\
\text { Technology Exhibits, sponsored by the government } \\
\text { information technology agencies and technology } \\
\text { companies; } \\
\text { Assignment } 4 \text { : Having students submit a 5-page } \\
\text { report through iCan5 on the exhibit that interested } \\
\text { them the most, summarizing why this specific exhibit } \\
\text { attracted them, what they learned, and what their } \\
\text { thoughts on future development and overall } \\
\text { perspectives about the Exhibits; }\end{array}$ & $\begin{array}{l}\text { Skills: Students are able to } \\
\text { (1) use Google Docs tools and } \\
\text { other web sharing services to } \\
\text { create images, documents, and } \\
\text { videos for personal use, sharing, } \\
\text { or collaboration, } \\
\text { (2) download and install other } \\
\text { web browsers, web software, and } \\
\text { apps for personal needs, } \\
\text { (3) use cloud storage websites } \\
\text { including Google, Dropbox, } \\
\text { Evernote, etc. to upload, } \\
\text { download, backup, share, and } \\
\text { collaborate on documents with } \\
\text { classmates and friends. }\end{array}$ \\
\hline
\end{tabular}


Table 2. Cont.

\begin{tabular}{|c|c|c|}
\hline Unit \# & Topics & $\begin{array}{l}\text { FIT Knowledge Components } \\
\text { and Expectations }\end{array}$ \\
\hline 4 & $\begin{array}{l}\text { d. Learning by doing: } \\
\text { Assignment 5: Using the picture and video editing } \\
\text { tools available on Panoramio, YouTube, and Google } \\
\text { Drive to create a short video at least one minute in } \\
\text { length. The completed video should include } \\
\text { background music, a title screen showing the } \\
\text { creator's name, creation date, etc. and pictures taken } \\
\text { on the campus using personal smartphone, and } \\
\text { ending with credits and notes illustrating the steps } \\
\text { taken to complete this project. Share the finished } \\
\text { project with the entire class on discussion forum; } \\
\text { e. Final Exam on VPN access and setup topics; }\end{array}$ & $\begin{array}{l}\text { Capabilities: Students can } \\
\text { (1) comprehend the necessity for } \\
\text { backing up the data created by or } \\
\text { important to oneself and choose } \\
\text { the best option to do so dutifully, } \\
\text { (2) use other authors' works while } \\
\text { avoiding IPR and CC violations, } \\
\text { (3) apply (reformulate) one's own } \\
\text { knowledge, skills, and past } \\
\text { experience to analyze issues } \\
\text { critically for solving network or } \\
\text { web technology related problems, } \\
\text { (4) utilize the available network } \\
\text { resources and applications further } \\
\text { to learn and to build new } \\
\text { knowledge, } \\
\text { (5) stay aware of the possibility of } \\
\text { cyber risks whenever being online, } \\
\text { (6) adapt easily to technology } \\
\text { changes, } \\
\text { (7) further enrich oneself } \\
\text { independently for pursuing future } \\
\text { academic and career success. }\end{array}$ \\
\hline
\end{tabular}

Note: Words in boldface denote item headings.

\subsection{Defining Learning Outcomes}

The enrolled students of this course were outside the computer science field and the majority were in soft science majors such as languages, social sciences, sports, laws, etc. Therefore, the authors of this article felt that it was necessary to come up with a set of learning outcomes that met common competency standards for all students. Based on the aims defined in the previous section and drawing on the ideas of the skills and the potential capabilities listed in the right most column of Table 2, we identified 20 learning outcomes. We hoped that they could help students gain foundational knowledge. With that, students can learn the technology used in their individual disciplines in the future. Furthermore, we hoped that this set of learning outcomes could help them gain the ability to perform immediate tasks such as making a successful network connection; creating, sharing, and collaborating on documents with others; using system security features to avoid cyber risks in an online environment; using works published by others with conscience and respect; socializing with family members, friends, and special interest groups without compromising their privacy. The 20 learning outcomes are listed in Table 3. They are grouped by course content topics. 
Table 3. Learning Outcomes for Network Resources and Applications.

\begin{tabular}{|c|c|}
\hline Course Content & Learning Outcome \\
\hline Network Basics & $\begin{array}{l}\text { 1. Students will understand the basic structure of a network and its } \\
\text { applications; } \\
\text { 2. Students will understand what IP Address, DNS, WWW, and Cloud } \\
\text { Computing are about; } \\
\text { 3. Students will understand the purposes of MAC (Media Access } \\
\text { Control) Address, DHCP (Dynamic Host Configuration Protocol), OSI } \\
\text { 7-layer structure; } \\
\text { 4. Students will understand the components required to establish a } \\
\text { network access from home and know how to resolve a network } \\
\text { connection problem; }\end{array}$ \\
\hline $\begin{array}{l}\text { Network Resources and } \\
\text { Applications }\end{array}$ & $\begin{array}{l}\text { 5. Students will know network resources and applications including } \\
\text { Facebook and PTT (a Taiwan-based electronic bulletin board); } \\
\text { 6. Students will know the purposes and functions of Evernote, Dropbox, } \\
\text { and Panoramio Applications; } \\
\text { 7. Students will be able to use essential email system features, including } \\
\text { importing and exporting mail and contacts; } \\
\text { 8. Students will know how to download college licensed software and } \\
\text { library resources for academic and personal use; } \\
\text { 9. Students will know how to use several popular web browsers and } \\
\text { their bookmark features; } \\
\text { 10. Students will understand the importance of backing up personal } \\
\text { computer data and know how to perform backup using external storage } \\
\text { media including CD disc, thumb drive, and cloud storage; } \\
\text { 11. Students will understand the differences between http:// and https://; }\end{array}$ \\
\hline $\begin{array}{l}\text { Emerging Network Resources } \\
\text { and Applications, Awareness } \\
\text { of Network Risks, and Safety }\end{array}$ & $\begin{array}{l}\text { 12. Students will understand what IPR and CC are about, as well as the } \\
\text { legal risks of downloading unauthorized online software, music, and } \\
\text { movies for personal possession and use; } \\
\text { 13. Students will understand the importance of protecting their personal } \\
\text { computers from unwanted intrusions by using an account password } \\
\text { created via secure password creation rules; } \\
\text { 14. Students will understand the necessity of changing their university } \\
\text { Single-Sign-On (LDAP) login password periodically to secure their } \\
\text { personal account access and data privacy; } \\
\text { 15. Students will understand the importance of changing their } \\
\text { passwords periodically in order to secure their personal computer and } \\
\text { online account access; } \\
\text { 16. Students will understand the importance of adopting a personal } \\
\text { password management strategy to secure their online account access; } \\
\text { 17. Students will know how to set up Facebook's device-specific logins } \\
\text { (personal computer, cellphone, iPad, etc.) and privacy protection; } \\
\text { 18. Students will understand what phishing is and how it works; } \\
\text { 19. Students will understand what Trojan and Zombie viruses are and } \\
\text { how they work; } \\
\text { 20. Students will know how to lock their computer properly when they } \\
\text { need to be away for a short period of time; }\end{array}$ \\
\hline
\end{tabular}

\subsection{Teaching Strategies}

According to FIT, the "project-based approach" was highly recommended. Thus, we developed five project-based assignments (see Table 2) based on our past teaching experience and new resources available to us. For each project, we first verified the existence of the three components of FIT, i.e., concepts, skills, and capabilities. We then decided on how we would teach, and which active learning strategies would better engage our students in learning the topics. Figure 1 shows an example illustrating the three components contained in Assignment 3. 


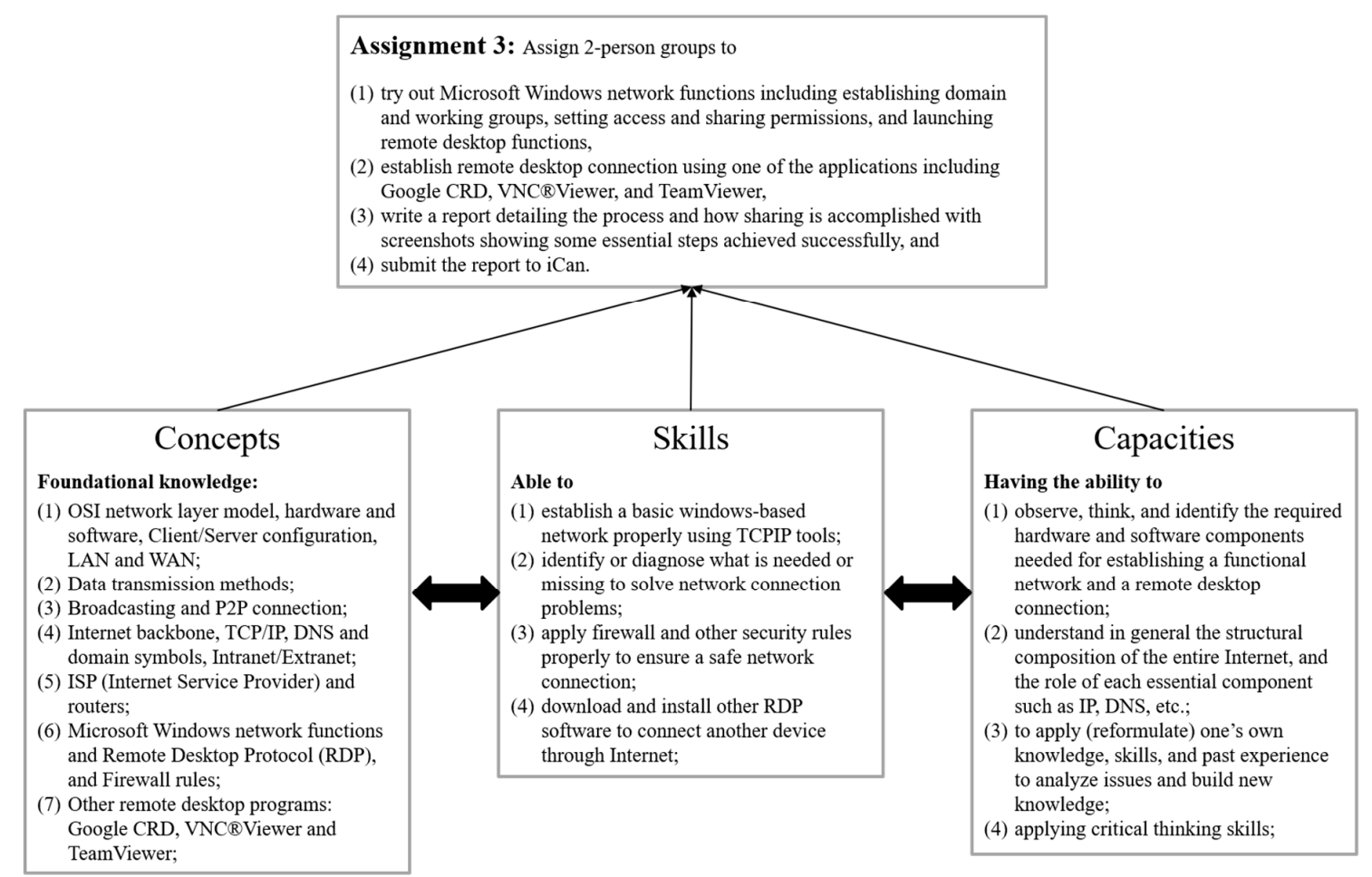

Figure 1. The three components of FIT Intellectual Framework for Assignment 3.

Table 1 lists the subtopics in italics, which are foundational concepts that can support the learning of skills and stimulate students' critical thinking and reasoning capabilities, allowing them to build new knowledge. The skill items, listed in the rightmost column in Table 2, help students understand foundational knowledge and potentially extend students' capacities to work on similar and more complex situations. The capacity items, shown in the same column, strengthen students' understanding of the concepts as well as students' confidence and fluency in using the skills.

After the 1994 Educational Reform movement, TMOE started advocating for active interactions in the classroom across the elementary and secondary education systems, hoping to shift the classroom dynamics from teacher-centeredness to student-centeredness. Unfortunately, the adoption of this paradigm has been very sluggish because societal culture in Taiwan is profoundly influenced by Confucius's teachings and social values, which are grounded in obedience, respect for elders, modesty, and harmony [32,33]. As a result, most students' attitude toward learning is passive. Having grown up under that influence, the authors of this article automatically inherited the same teaching style used in our school and college years. Lecture- and textbook-based teaching style with some hands-on demonstrations to help students memorize the steps required to perform computer tasks was the main teaching method that the authors had been using.

Nevertheless, the authors decided to try out some active learning strategies. They were summarized as follow:

1. Learning by visual presentations via PowerPoint slides and selected YouTube videos:

(a) Assignment 2: Evolution of the Internet and its impacts;

(b) Network safety, security risks, cyber-attacks, and case studies;

(c) Cloud computing basics and its applications and impacts;

(d) Demonstrating prevention methods using secure password rules, and ISMS, etc.;

2. Learning by doing:

(a) Assignment 3: Working as a team to establish a secure network using Microsoft Windows network functions and remote desktop connection with other applications; 
(b) Practicing email system basics and advanced features;

(c) Learning Google Docs productivity, sharing, and social tools;

(d) Creating a simple web page with http:// and https:// access, respectively, and exploring the security risks between the two;

(e) Browsing browser-related security and privacy controls;

(f) Assignment 5: Using smartphone, Panoramio, and YouTube editing tools to create a short video;

3. Learning by reading and writing:

(a) Read selected articles on Intellectual Property Rights (IPR) and Creative Commons (CC) Licenses, and submit a written report;

(b) Write a report on each of the topics presented through visual presentation;

4. Learning by observation and exploration:

(a) Assignment 1: Finding the configuration of the Internet connection at home, dorm, or apartment, and submitting a written summary report;

(b) Assignment 4: Taking students to visit a network technology exhibit and submit a written report.

In addition to the above strategies, the authors also adopted pausing techniques when lecturing in conjunction with visual presentations. After lecturing 10 to $15 \mathrm{~min}$, the authors would pause to give students opportunities to ask questions, reflect, discuss, analyze, and brainstorm. Occasionally, students were asked to respond with their point of view voluntarily in class or in writing. The traditional evaluation methods including homework, quizzes, midterm and final exams were also used to enhance students' understanding of the underlying concepts and associated terminology.

The authors also employed technology-enabled active learning tools available on iCan learning system adopted by the University in early 2010s. Like other LMS, it offered many basic tools for instructors, students, and system managers to use, respectively. The communications tools between instructors and students included discussion forum, email-based instant response system, homework submission, taking quizzes, and grading system. However, the authors chose the discussion forum as an additional pedagogical tool to encourage students' interaction and engagement due to its ease of use.

\section{Methodology}

\subsection{Research Design (Objectives, Pre-Tests, Post-Tests, Questionaire)}

To gauge the effectiveness of our efforts, we used a pre-test and post-test method. Our objectives were to use a pre-test to find out if students already had some prior knowledge before taking this course; a post-test was used to find out whether students had gained significant new knowledge or made significant improvement after taking this course; we then used Likert-Scale statistical median value to evaluate the collected data.

In order to keep the tests free from bias, one of the authors of this article was responsible for conducting the surveys. The tests were created on Goggle Survey website. The URL links to the two surveys were sent to all students enrolled in the four classes (two for each semester) of the 2012-2013 academic year. There was a total of 240 students enrolled in these four classes. They were encouraged to take the surveys voluntarily at the beginning and at the end of each semester.

Although there were 240 students, only $177(74 \%)$ students properly completed both tests. The surveys were anonymous but did ask students to provide their individual University ID numbers. This was to ensure that each valid ID did link to a pre-test and a post-test completed by the same ID holder. The pre-test's URL was given to students in the second week of each semester, while the 
post-test's URL was given in the last week of each semester. Students were given two weeks to submit their questionnaires.

Regarding the questionnaire's questions, we searched the literature and did not find a set of standards for testing competencies related to understanding network technology underpinnings and the effective use of network resources and applications covered by this course. Therefore, we decided to use the 20 learning outcomes developed for this course (see Table 3) as survey questions, except that first person and present tense were used for each question (i.e., "I understand" instead of "Students will understand"). Likert-Scale styled multiple-choice answers were provided for students to choose from and only one choice for each question was permitted. Depending on the nature of the questions, some questions had 3 choices while others had up to 6 choices.

\subsection{Analyses and Results}

Our first step was sorting out the returned questionnaires by students' University ID numbers to ensure the tests were completed properly by the same ID holder. We then applied a Likert-Scale median statistical method to weigh the responses chosen by students. Table 4 shows the results of students' prior knowledge before taking this course, as well as the results of how they perceived their understanding after taking this course.

Table 4. Pre-Test and Post-Test Results by Number of Students and Corresponding Percentages.

\begin{tabular}{|c|c|c|c|c|c|}
\hline \multirow{3}{*}{$\begin{array}{l}\text { Learning Outcome } \\
\text { Question }\end{array}$} & \multirow{3}{*}{ Median } & \multicolumn{4}{|c|}{ Students Who Chose the Response Better Than the Median } \\
\hline & & \multicolumn{2}{|c|}{ Pre-Test } & \multicolumn{2}{|c|}{ Post-Test } \\
\hline & & \# & $\%(n=177)$ & \# & $\%(n=177)$ \\
\hline 1 & 3 & 13 & $7.3 \%$ & 106 & $59.4 \%$ \\
\hline 2 & 3 & 3 & $1.7 \%$ & 144 & $81.4 \%$ \\
\hline 3 & 3 & 13 & $7.3 \%$ & 123 & $69.5 \%$ \\
\hline 4 & 3 & 16 & $9.0 \%$ & 117 & $66.1 \%$ \\
\hline 5 & 3 & 51 & $28.8 \%$ & 168 & $94.9 \%$ \\
\hline 6 & 2.5 & 70 & $39.5 \%$ & 172 & $97.2 \%$ \\
\hline 7 & 2.5 & 126 & $71.1 \%$ & 151 & $85.3 \%$ \\
\hline 8 & 2 & 61 & $34.4 \%$ & 136 & $76.8 \%$ \\
\hline 9 & 2.5 & 148 & $83.6 \%$ & 167 & $94.4 \%$ \\
\hline 10 & 3.5 & 56 & $31.6 \%$ & 119 & $67.2 \%$ \\
\hline 11 & 2 & 21 & $11.9 \%$ & 110 & $62.1 \%$ \\
\hline 12 & 3 & 36 & $20.3 \%$ & 104 & $58.8 \%$ \\
\hline 13 & 2.5 & 86 & $48.6 \%$ & 141 & $79.7 \%$ \\
\hline 14 & 3 & 14 & $7.9 \%$ & 42 & $23.7 \%$ \\
\hline 15 & 2.5 & 24 & $13.6 \%$ & 53 & $29.9 \%$ \\
\hline 16 & 2 & 109 & $61.6 \%$ & 140 & $79.1 \%$ \\
\hline 17 & 2.5 & 81 & $45.8 \%$ & 120 & $67.8 \%$ \\
\hline 18 & 2 & 35 & $19.8 \%$ & 149 & $84.2 \%$ \\
\hline 19 & 2 & 35 & $19.8 \%$ & 150 & $84.7 \%$ \\
\hline 20 & 2 & 34 & $19.2 \%$ & 82 & $46.3 \%$ \\
\hline
\end{tabular}

Figure 2 shows the percentages of students who felt that their prior knowledge was better than the median before taking this course. Regarding Network Basics (Questions 1-4), the first question asked students' familiarity with basic network structure and its applications in general. Less than $8 \%$ 
of students perceived themselves to have familiarity better than the median. IP address, DNS, WWW (Question 2), and MAC Address, OSI, etc. (Question 3) were all specific elements of a functioning network. However, less than $2 \%$ of students felt they had prior knowledge better than the median for Question 2\% and 7.3\% of students for Question 3. Additionally, only 9\% of students knew about the basic configuration of a network connection used in their dorm or home and how to solve a connection problem when necessary (Question 4).

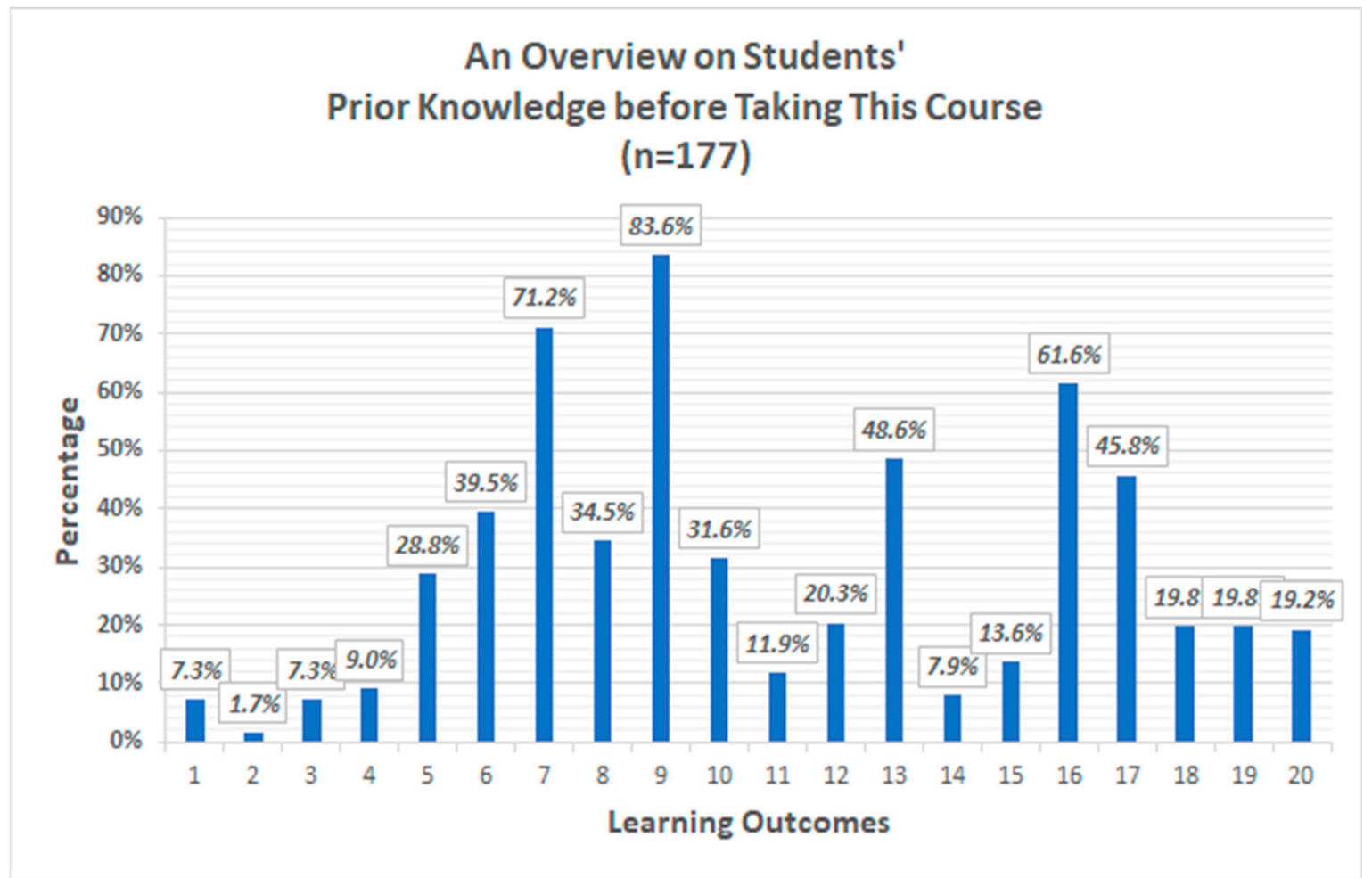

Figure 2. Pre-Test Results. Notes: Questions 1-4 were in Network Basics content category; questions 5-11 in Network Resources \& Applications category; questions 12-20 in Awareness of Network Risks and Safety category.

With Network Resources and Applications (Questions 5-11), the results of Questions 7 (71.2\%) and $9(83.6 \%)$ in Figure 2 stood out, indicating that a great majority of students were already familiar with email systems and web browsers, respectively. This is understandable, as two areas have grown rapidly and become indispensable day-to-day tools for many of us. However, less than $29 \%$ (Question 5) of students knew about sharing and community-building tools, including Facebook and PTT digital bulletin board, and less than $40 \%$ (Question 6) of students were familiar with emerging network applications such as Evernote, DropBox, and Panoramio. Most surprisingly, only a minority $(34.5 \%)$ of students knew the availability of the licensed software and library online research resources purchased by the University for student use (Question 8). About 32\% (Question 10) of students knew the importance of backing up their personal and course related documents using CD discs, flash drives, and/or cloud storages. About 12\% (Question 11) of students understood the security differences between http and https.

For the Awareness of Network Risks and Safety (Questions 12-20), the results shown in Figure 2 stood out at various height levels. The result of Question 16 was $61.6 \%$, whereas the result of Question 14 was $7.9 \%$. However, for Question 16, the majority of students dutifully kept their passwords only to themselves. As to password change frequency for their personal online accounts (Question 14) and individual university Single-Sign-On accounts (Question 15), a small minority (7.9\% and 13.6\%) of students had changed at least once every year, respectively. Nearly half ( $48.6 \%$ and $45.8 \%)$ of students 
knew how and why to apply security features to protect their personal computers (Question 13) and their own Facebook account and privacy (Question 17). Regarding Question 18 (Phishing, Trojan horse, etc.) and Questions 19 (Zombie and other cyber-attacks), only a minority (both at 19.8\%) of students were aware of these risks, respectively. Similarly, only a minority (20.3\%) of students were aware of copyright-related issues when downloading materials online (Question 12). Question 20 asked students what they would do with a public or a personal computer that they were using when they needed to be away for a short period. Again, only a minority of students $(19.2 \%)$ knew to put their computer screens in lock-up mode to protect their personal data and privacy.

In Figure 3, we put the results of pre-test and post-test side by side to compare students' learning progress. It is evident that the students' knowledge increased after taking this course. In the Network Basics category (Questions 1-4), the results indicated that nearly 60 to $82 \%$ of students understood the content better than the median level. This is a 50 to $70 \%$ increase. Apparently, most students had gained knowledge in this content area.

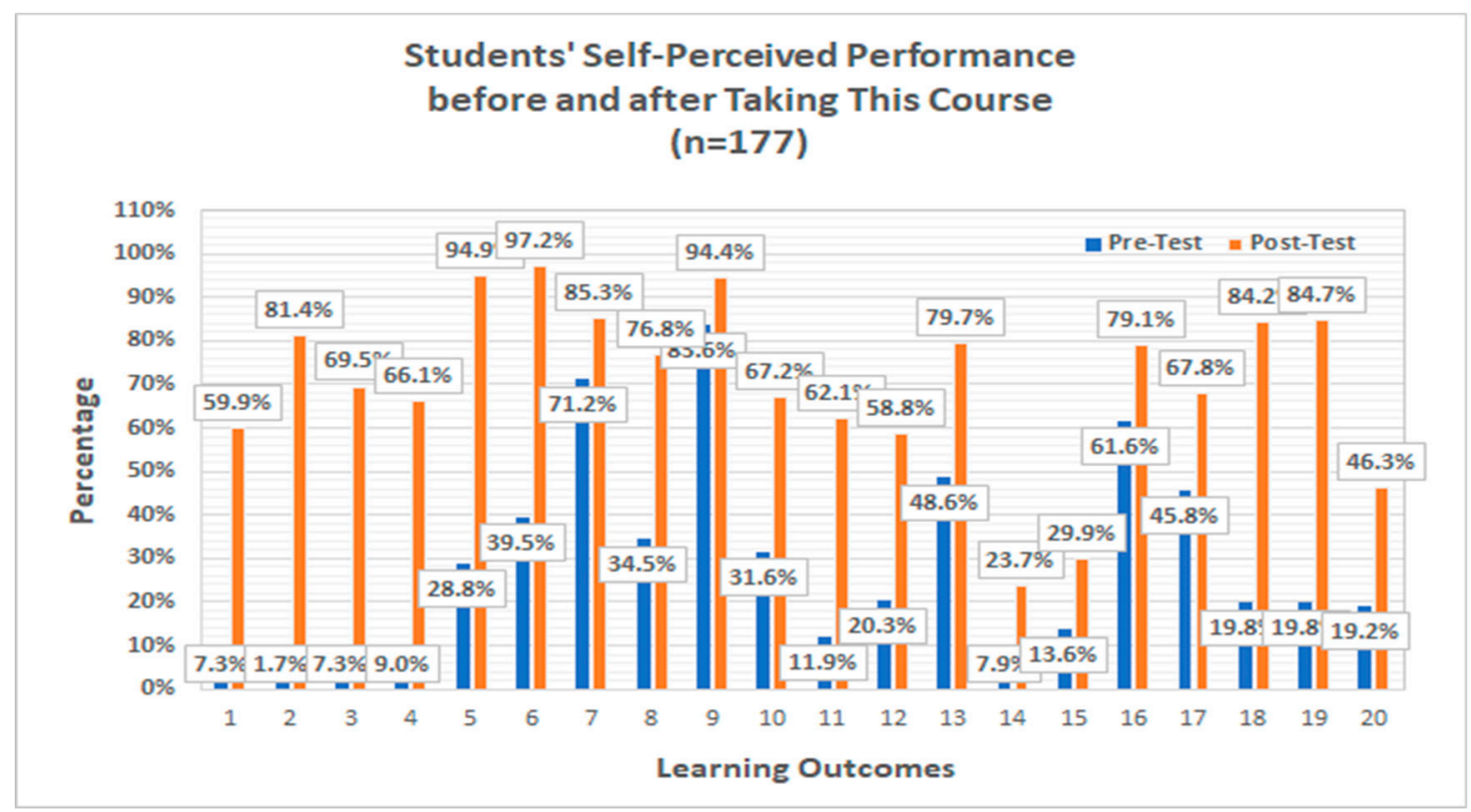

Figure 3. A Comparison of Pre-Test and Post-Test Results. Notes: Questions 1-4 were in Network Basics content category; questions 5-11 in Network Resources \& Applications category; questions 12-20 in Awareness of Network Risks and Safety category.

As for Network Resources and Applications (Question 5-11), the results of Questions 5, 6, 8, and 11 also increased between $42 \%$ and $66 \%$. Particularly, an overwhelming majority of students rated their understanding of Question 5 (94.9\%) and Question 6 (97.2\%) better than the median. Even with the email systems (Question 7) and web browsers (Question 9), which were already rated high $(71.2 \%$ and $83.6 \%$ ) in pre-test, the results showed $14.1 \%$ and $10.8 \%$ increases, respectively. For Question 10, the results $(67.2 \%)$ also indicated that the majority of students had learned better than the median after taking this course.

In Awareness of Network Risks and Safety category (Questions 12-20), all questions except 14, 15, and 20 (Questions 12, 13 and 16-19), indicated that the majority (58\% or higher) of students rated their knowledge better than the median after taking this course. In particular, Questions 18 (64.4\%) and 19 (64.9\%) dealing with phishing, and cyber risks and safety had more than $64 \%$ increase. However, the results of Questions $14(23.7 \%)$ and $15(29.9 \%)$ show an increase of only a little over $15 \%$, as opposed to their pre-test counterparts $(7.9 \%$ and $13.6 \%)$. These two questions were about password change frequency. Similarly, the result of Question 20 (46.3\%) dealing with locking-up computer screens did not reach $50 \%$, although there was a $27 \%$ increase from its pre-test result (19.2\%). Raising students' 
awareness of cyber risks and safety was one of the aims of this course. In contrast with the results of Questions 18 and 19, it seems that students did improve their understanding of cyber risks but were still insufficient in taking preventive actions. With Question 12, related to IPR and CC, the result $(58.8 \%)$ indicated that a minority of students still did not have awareness better than the median, although there was a $38.5 \%$ increase from its pre-test result $(20.3 \%)$.

The post-test results shown in Figure 3 looked convincing, indicating that the efforts put forth by the authors of this article in restructuring course content and retooling teaching with active learning strategies contributed to this impressive result. However, we added two additional questions in post-test questionnaire to ascertain if our effort did help engage students in learning and enhancing their learning experience. The first question asked students how they would grade their own overall performance of this course. The results showed that more than $90 \%$ of students gave themselves a score of 60 or higher. Among them, in fact 50\% gave themselves an 80 and 10\% gave themselves a 100. This result was consistent with the overall results of the post-test in demonstrating students' impressive progress, although it was a little higher. However, it did indicate that most students were enthusiastically engaged and satisfied with what was taught and how the course was delivered.

The second question asked students to rate the usefulness of this course in supporting their future job seeking and whether they had learned enough from this course. Unfortunately, only a total of 78 $(32.5 \%)$ students responded to this question. Among them, $73 \%$ of students rated this course most useful for future job seeking and felt they had learned a lot, while $27 \%$ of students rated the course useful but had felt they had learned limitedly.

We feel that the survey was reliable because the sample size (177) was large enough. In addition, the tests were conducted online and administered by the co-author without sharing the survey results until grades were turned in. All in all, the results were impressive in terms of course content reorganization together with the adopted active learning strategies for teaching this course. Additionally, the test results were consistent with the findings (i.e., increased learning outcomes) presented in the active learning literature $[25,27]$.

\subsection{Limitations and Implications}

Because the survey questions were specifically designed for this course, its applicability thus was limited. Some questions may need to be replaced or changed when corresponding resources and applications become obsolete. Our surveys could only test the effectiveness of the changes that we made for teaching this course. Those changes were restructuring the course content and adopting active learning strategies. Therefore, the test results could not show which change was more effective than the other.

Certainly, there are areas that need attention for improvement and further research. Based on our experience, areas related to teaching and learning assessment tools and making Chinese students actively engaged through interactions are much needed for future research.

Like many authors cited in the literature review section, the authors of this article would also like to encourage those teaching faculty who have not yet wet their feet to jump in as soon as possible. Today, constant change is the norm. Having the ability to adapt to these changes by using our intellectual capacities is the best way to sustain ourselves and to live through these changes with a peaceful mind. That said, we believe that our approach to teaching this course is a sustainable one.

Although the definition of IT literacy was conceived in 1999, its central theme is in fact parallel to that of sustainable education, i.e., becoming adaptable to changes via a deep conceptual understanding of one's knowledge domain, skills, and intellectual capacities to sustainably solve more complicated problems. With respect to designing technology curriculum, van den Branden ([34] pp. 5473-5474) suggested that "if the education of 20th century was low-tech, sustainable education for 21st century will need to be multimodal and high-tech." That said, FIT intellectual framework fits right in to help curriculum design. 
Van den Branden ([34] p. 5480) also stressed that "Teachers make the crucial difference" in achieving the goals of sustainable education. That is because teachers "are in the privileged position" to design and organize "meaningful learning activities" to engage students actively in renewing their learning energy to learn "high-order thinking" skills, refreshing their "energy-learning cycle" to learn further with confidence, and applying prior knowledge and past experience creatively to adapt to changes.

\section{Conclusions}

This study presents an approach to information technology courses that can improve students' learning outcomes. The approach applies the concept of FIT intellectual framework to construct course content and adopts active learning strategies to deliver the course. Test results prove that this approach is effective and convincing.

FIT, fluency with technology, advocates the ability to use technology fluently, as well as the ability to adapt to technology changes through constant learning. The final goal is to ultimately cultivate a lifelong learner. The intellectual framework of FIT is a practical tool with three co-equal components (i.e., concepts, skills, and capacities). Each represents a kind of knowledge and each reinforces the other. Concepts can facilitate the understanding of the foundational knowledge and the learning of skills, and further expand intellectual capacity. Skills strengthen conceptual understanding, and the building of new knowledge and experience, which in turn expand the capacity itself as well. Capacities facilitate the learning of concepts and skills more effectively. In such a manner, a FIT individual can use technology fluently, be relevant in the technology job market, stay on top of changes, and make smooth adjustments to adapt when change happens.

To deliver a FIT-based course effectively, applying active learning strategies pedagogically is necessary. Learning by doing can engage students, as well as enhance their experience, reflection, and knowledge retention. Learning by observation and exploration help stimulate and inspire students' learning engagement and high-order thinking ability. Among others, these are strategies specifically used by this study.

Certainly, for instructors, a deep conceptual understanding in the domains of IT, active learning, and teaching technology would better facilitate the course planning and designing process. However, with the Fourth Industry Revolution upon us, it is beneficial to design a sustainable hi-tech technology course using the concept of active learning and the FIT intellectual framework. With these methods, our students are able to learn self-sustainably even after they leave the classroom, an important skill in today's quickly changing world.

Author Contributions: Conceptualization, T.-M.P.; methodology, T.-M.P.; validation, T.-M.P. and K.-C.F.; formal analysis, T.-M.P.; writing—original draft preparation, T.-M.P.; writing—review and editing, T.-M.P. and K.-C.F.; supervision, K.-C.F. All authors have read and agreed to the published version of the manuscript.

Funding: This research received no external funding.

Conflicts of Interest: The authors declare no conflicts of interest.

\section{References}

1. Vadantham, A.; Breeden, L. Networking for K-12 education: The Federal perspective. Internet Res. Electron. Netw. Appl. Policy 1995, 5, 29-39. [CrossRef]

2. Zhang, K.; Hung, J. E-Learning in Taiwan's higher education: Policies, practices, and problems. Int. J. Inf. Commun. Technol. 2006, 2, 37-52. [CrossRef]

3. Lu, M. Higher Education Reform in the Republic of China; Minister of Education: Taiwan, China, 2001. Available online: https://english.moe.gov.tw/cp-13-14087-CF128-2.html (accessed on 18 March 2020).

4. Gong, G. Taiwan Internet Evolution: Status Report. Information Technology Promotion Division, Institute for Information Industry (III). Available online: http://web.simmons.edu/ \{\}chen/nit/NIT\T1\textquoteright98/ 98-051-Gong.html (accessed on 18 March 2020).

5. Tu, C.; Twu, H. Educational technology in Taiwan. Educ. Media Int. 2002, 39, 153-164. 
6. TMOE (Taiwan's Ministry of Education). Information and Internet Education. 2005. Available online: https://english.moe.gov.tw/cp-13-13941-1E58B-1.html (accessed on 18 March 2020).

7. World Economic Forum. The Global Information Technology Report 2019. Available online: http://www3. weforum.org/docs/WEF_TheGlobalCompetitivenessReport2019.pdf (accessed on 18 March 2020).

8. Fu Jen Catholic University. About Fu Jen: Facts at a Glance. 2020. Available online: http://www.fju.edu.tw/ aboutFju.jsp?labelID=22 (accessed on 13 May 2020).

9. Holistic Education Center, Fu Jen Catholic University. 2020. Available online: http://www.fju.edu.tw/ academics.jsp?labelID=13 (accessed on 13 May 2020).

10. Zhen, R.W. A Study on the Effectiveness Evaluation and Employment of the Young People's Employment; Executive Yuan Youth Counseling Committee: Taiwan, China, 2011.

11. Sullivan, M.A.; Dilek, Y. Enhancing scientific literacy through the use of information technology in introductory geoscience classes. J. Geosci. Educ. 1997, 45, 308-313. [CrossRef]

12. van Eijck, M.; Roth, W. Rethinking the role of information technology-based research tools in students development of scientific literacy. J. Sci. Educ. Technol. 2007, 16, 225-238. [CrossRef]

13. Bauer, A.M.; Thielk, S.M.; Katon, W.; Unutzer, J.; Arean, P. Aligning health information technologies with effective service delivery models to improve chronic disease care. Prev. Med. 2014, 66, 167-172. [CrossRef]

14. Epperson, A. Computer literacy revisited: A comprehensive investigation of computer literacy. ACM Inroads 2010, 1, 30-33. [CrossRef]

15. Hoffman, M.; Blake, J. Computer literacy: Today and tomorrow. J. Comput. Sci. Coll. 2003, 18, $221-233$.

16. Isokpehi, R.D.; Thomas, B.N.; Ojo, A.K.; Sofoluwe, A.B.; Coker, A.O. Information technology literacy among Nigerian microbiology students and professionals. World J. Microbiol. Biotechnol. 2000, 16, 423-4214. [CrossRef]

17. King, K.M. Evolution of the computer literacy. EDUCOM Bull. 1985, 20, 18-21.

18. Perez, J.; Murray, M. Computer for the masses: Extending the computer science curriculum with information technology literacy. Consort. Comput. Sci. Coll. 2008, 22, 220-226.

19. Osborne, C. Planning for IT literacy in an institution of higher education: A Case Study. Comput. J. 1993, 36, 343-350. [CrossRef]

20. Halaris, A. Towards a definition of computing literacy for the liberal arts environment. ACM SIGCSE Bull. 1995, 17, 320-326.

21. NRC (National Research Council). Being Fluent with Information Technology; National Academic Press: Washington, DC, USA, 1999.

22. Bonwell, C.C.; Eison, J.A. Active learning: Creating excitement in the classroom. In ASHE-ERIC on Higher Education Reports; George Washington Univ., School of Education and Human Development: Washington, DC, USA, 1991.

23. Cattaneo, K.H. Telling active learning pedagogies apart: From theory to practice. J. New Approaches Educ. Res. 2017, 6, 144-152. [CrossRef]

24. Mitchell, A.; Petter, S.; Harris, A.I. Learning by doing: Twenty successful active learning exercises for information systems courses. J. Inf. Technol. Educ. Innov. Pract. 2017, 16, 21-46. [CrossRef]

25. Freeman, S.; Eddy, S.L.; McDonough, M.; Smith, M.K.; Okoroafor, N.; Jordt, H.; Wenderoth, M.P. Active learning increases student performance in science, engineering, and mathematics. Proc. Natl. Acad. Sci. USA 2014, 111, 8410-8415. [CrossRef]

26. Patton, C.M. Employing active learning strategies to become the facilitator, not the authoritarian: A literature review. J. Instr. Res. 2015, 4, 134-141. [CrossRef]

27. Prince, M. Does active learning work? A review of the research. J. Eng. Educ. 2004, 93, 223-231. [CrossRef]

28. Alavi, M. Computer-mediated collaborative learning: An Empirical Evaluation. MIS Q. 1994, 18, 159-174. [CrossRef]

29. Reid, L.A.; Weber, C.M. Using technology-Enabled active learning tools to introduce business ethics topics in business law courses: A few practical examples. J. Leg. Stud. Educ. 2008, 25, 283-305. [CrossRef]

30. Snowball, J.; Mostert, M. Introducing a learning management system in a large first year class: Impact on lectures and students. S. Afr. J. High. Educ. 2010, 24, 818-831. [CrossRef]

31. Schroeder-Moreno, M.S. Enhancing active and interactive learning online-Lessons learned from an online introductory agroecology course. N. Am. Coll. Teach. Agric. J. 2010, 54, 21-30. 
32. Huang, Y.; Asghar, A. Science education reform in Confucian learning cultures: Teachers' perspectives on policy and practice in Taiwan. Cult. Stud. Sci. Educ. 2018, 13, 101-131. [CrossRef]

33. Teng, L.Y. Infusing a collaborative learning curriculum to enhance active college learning. Coll. Q. 2006, 9, $1-18$.

34. Van den Branden, K. Sustainable education: Exploiting students' energy for learning as a renewable resource. Sustainability 2015, 7, 5471-5487. [CrossRef]

(C) 2020 by the authors. Licensee MDPI, Basel, Switzerland. This article is an open access article distributed under the terms and conditions of the Creative Commons Attribution (CC BY) license (http://creativecommons.org/licenses/by/4.0/). 